Western University

Scholarship@Western

Brain and Mind Institute Researchers'

Publications

Brain and Mind Institute

3-1-2018

\title{
Cortical and thalamic connectivity to the second auditory cortex of the cat is resilient to the onset of deafness.
}

\author{
Blake E Butler \\ Cerebral Systems Laboratory, University of Western Ontario, London, ON, N6A 5C2, Canada \& Department \\ of Psychology, University of Western Ontario, London, ON, N6A 5C2, Canada \& Brain and Mind Institute, \\ University of Western Ontario, London, ON, N6A 5B7, Canada \& National Centre for Audiology, University \\ of Western Ontario, London, ON, N6G 1H1, Canada, bbutler9@uwo.ca
}

Alexandra de la Rua

Cerebral Systems Laboratory, University of Western Ontario, London, ON, N6A 5C2, Canada \&

Neuroscience Undergraduate Program, University of Western Ontario, London, ON, N6A 3K7, Canada

Taylor Ward-Able

Cerebral Systems Laboratory, University of Western Ontario, London, ON, N6A 5C2, Canada \&

Neuroscience Undergraduate Program, University of Western Ontario, London, ON, N6A 3K7, Canada

Stephen G Lomber

Cerebral Systems Laboratory, University of Western Ontario, London, ON, N6A 5C2, Canada \& Department of Psychology, University of Western Ontario, London, ON, N6A 5C2, Canada \& Brain and Mind Institute, University of Western Ontario, London, ON, N6A 5B7, Canada \& National Centre for Audiology, University of Western Ontario, London, ON, N6G 1H1, Canada \& Department of Physiology and Pharmacology, University of Western Ontario, London, ON, N6A 5C1, Canada

Follow this and additional works at: https://ir.lib.uwo.ca/brainpub

Part of the Neurosciences Commons, and the Psychology Commons

Citation of this paper:

Butler, Blake E; de la Rua, Alexandra; Ward-Able, Taylor; and Lomber, Stephen G, "Cortical and thalamic connectivity to the second auditory cortex of the cat is resilient to the onset of deafness." (2018). Brain and Mind Institute Researchers' Publications. 103.

https://ir.lib.uwo.ca/brainpub/103 


\title{
Cortical and thalamic connectivity to the second auditory cortex of the cat is resilient to the onset of deafness
}

\author{
Blake E. Butler ${ }^{1,2,3,4}$ D Alexandra de la Rua $^{1,5} \cdot$ Taylor Ward-Able $^{1,5}$. \\ Stephen G. Lomber ${ }^{1,2,3,4,6}$ (D)
}

Received: 17 March 2017/Accepted: 4 September 2017/Published online: 22 September 2017

(C) Springer-Verlag GmbH Germany 2017

\begin{abstract}
It has been well established that following sensory loss, cortical areas that would normally be involved in perceiving stimuli in the absent modality are recruited to subserve the remaining senses. Despite this compensatory functional reorganization, there is little evidence to date for any substantial change in the patterns of anatomical connectivity between sensory cortices. However, while many auditory areas are contracted in the deaf, the second auditory cortex (A2) of the cat undergoes a volumetric expansion following hearing loss, suggesting this cortical area may demonstrate a region-specific pattern of structural reorganization. To address this hypothesis, and to complement existing literature on connectivity within auditory cortex, we injected a retrograde neuronal tracer across the breadth and cortical thickness of $\mathrm{A} 2$ to provide the first comprehensive quantification of projections from cortical and thalamic auditory and non-auditory regions to the second auditory cortex, and to determine how these patterns are affected by the onset of deafness. Neural
\end{abstract}

Blake E. Butler

bbutler9@uwo.ca

1 Cerebral Systems Laboratory, University of Western Ontario, London, ON N6A 5C2, Canada

2 Department of Psychology, University of Western Ontario, London, ON N6A 5C2, Canada

3 Brain and Mind Institute, University of Western Ontario, London, ON N6A 5B7, Canada

4 National Centre for Audiology, University of Western Ontario, London, ON N6G 1H1, Canada

5 Neuroscience Undergraduate Program, University of Western Ontario, London, ON N6A 3K7, Canada

6 Department of Physiology and Pharmacology, University of Western Ontario, London, ON N6A 5C1, Canada projections arising from auditory, visual, somatomotor, and limbic cortices, as well as thalamic nuclei, were compared across normal hearing, early-deaf, and late-deaf animals. The results demonstrate that, despite previously identified changes in A2 volume, the pattern of projections into this cortical region are unaffected by the onset of hearing loss. These results fail to support the idea that crossmodal plasticity reflects changes in the pattern of projections between cortical regions and provides evidence that the pattern of connectivity that supports normal hearing is retained in the deaf brain.

Keywords Anatomical connectivity · Auditory deprivation · BDA $\cdot$ Crossmodal plasticity

$\begin{array}{ll}\text { Abbreviations } \\ \text { AAF } & \text { Anterior auditory field } \\ \text { AES } & \text { Anterior ectosylvian sulcus } \\ \text { AEV } & \text { Anterior ectosylvian visual area } \\ \text { ABR } & \text { Auditory brainstem response } \\ \text { ALLS } & \text { Anterolateral lateral suprasylvian area } \\ \text { AMLS } & \text { Anteromedial lateral suprasylvian area } \\ \text { A1 } & \text { Primary auditory cortex } \\ \text { A2 } & \text { Second auditory cortex } \\ \text { BDA } & \text { Biotinylated dextran amine } \\ \text { CGP } & \text { Posterior cingulate area } \\ \text { CVA } & \text { Cingulate visual area } \\ \text { dB } & \text { Decibel } \\ \text { DLS } & \text { Dorsal lateral suprasylvian area } \\ \text { dPE } & \text { Dorsal division of the posterior ectosylvian } \\ & \text { gyrus } \\ \text { DZ } & \text { Dorsal zone of auditory cortex } \\ \text { ED } & \text { Early-deaf } \\ \text { EEG } & \text { Electroencephalography }\end{array}$

\section{Abbreviations}

AAF

Anterior auditory field

Anterior ectosylvian sulcus

Anterior ectosylvian visual area

Auditory brainstem response

Anterolateral lateral suprasylvian area

AMLS

A1

A2

Primary auditory cortex

BDA

CGP

Biotinylated dextran amine

CVA

Cingulate visual area

DLS Dorsal lateral suprasylvian area

dPE Dorsal division of the posterior ectosylvian

DZ Dorsal zone of auditory cortex

EEG Electroencephalography 
EPp Posterior aspect of the posterior ectosylvian gyrus

fAES Auditory field of the anterior ectosylvian sulcus

IN Insular auditory cortical area

iPE Intermediate division of the posterior ectosylvian gyrus

LD Late-deaf

LP Lateral posterior nucleus

MGBd Dorsal division of the medial geniculate body

MGBm Medial division of the medial geniculate body

MGBV Ventral division of the medial geniculate body

MZ Multisensory zone

$\mathrm{NH} \quad$ Normal hearing

nHL Normal hearing level

PAF Posterior auditory field

PES Posterior ectosylvian sulcus

PLLS Posterolateral lateral suprasylvian area

PMLS Posteromedial lateral suprasylvian area

PO Posterior complex

PS Posterior suprasylvian area

Psb Presubiculum

Rsp Posterior limb of the rostral suprasylvian sulcus

SGN Suprageniculate nucleus

SVA Splenial visual area

S2 Second somatosensory area

S2m Medial division of the second somatosensory area

S3 Third somatosensory area

S4 Fourth somatosensory area

S5 Fifth somatosensory area

T Temporal auditory cortical area

VAF Ventral auditory field

VLS Ventral lateral suprasylvian area

VPAF Ventral posterior auditory field

vPE Ventral division of the posterior ectosylvian gyrus

\section{Introduction}

The term neuroplasticity refers to the impressive capacity of the brain to be shaped by experience. In the case of auditory perception, this flexibility allows stimulus encoding to be optimized for those sounds encountered most frequently in our environment. Over time, this flexibility diminishes in favour of stability (see Takesian and Hensch 2013 for review). In the case of normal development, auditory pathways from cochlea to cortex are established prior to the onset of hearing (O'Leary et al. 2007; Jones et al. 2007), and are structurally and functionally refined by stimulus-evoked activity (Dahmen and King 2007; Eggermont 2008). While this experience-dependent reorganization typically leads to optimal function across the brain (Fig. 1), it also leaves sensory pathways vulnerable to periods of abnormal experience. For example, there is a large body of evidence suggesting that following periods of deafness, auditory cortical regions are crossmodally reorganized to process visual (Neville et al. 1983; Finney et al. 2001, 2003; Lee et al. 2001; Lambertz et al. 2005; Pekkola et al. 2005; Lomber et al. 2010; Meredith et al. 2011; Karns et al. 2012) or somatosensory stimuli (Levänen et al. 1998; Levänen and Hamdorf 2001; Auer et al. 2007; Allman et al. 2009; Bhattacharjee et al. 2010; Meredith and Lomber 2011; Karns et al. 2012).

In addition to functional reassignment, there is some evidence for changes in the structure of auditory cortical fields following deafness. For example, differential patterns of SMI-32 labelling provide clear borders between regions of auditory cortex (Mellott et al. 2010); Wong et al. (2014) used these labelling profiles to quantify changes in the areal cartography of auditory cortex following early- and lateonset deafness in the cat. While the total fractional volume occupied by auditory cortex was not shown to be altered by the onset of deafness, some auditory cortical fields revealed age-related changes following hearing loss. For example, the primary auditory cortex of the cat (A1) showed a decreased volume following both early- and late-onset hearing loss; this was in accordance with anatomical (Chabot et al. 2015) and functional studies showing little or no crossmodal reorganization in this field (Stewart and Starr 1970; Kral et al. 2003). However, Wong et al. also noted a small number of auditory cortical fields that occupied larger fractional volumes in deaf animals than in controls. For example, the volume of the second auditory cortex (A2) was significantly greater following early-onset hearing loss than in normal hearing animals as the result of a dorsal shift in the A1-A2 border (Fig. 2).

That early-onset deafness induces changes differing by area is not surprising; across sensory systems, it has been suggested that the potential for neuroplastic reorganization increases at higher levels of the functional hierarchy. Moreover, the absence of structural changes in the pattern of projections to some fields of auditory cortex (A1-Chabot et al. 2015; fAES_-Meredith et al. 2016; PAF_-Butler et al. 2016a) and presence of small but significant changes in others (DZ_Kok et al. 2014; AAF_-Wong et al. 2015) is direct evidence in support of field-specific effects.

In their hierarchy of cat auditory cortex, Lee and Winer (2011) describe A2 as a mid-level area in the ventral processing stream that serves to relay information between core areas and high-level multisensory and limbic fields of auditory cortex. Evidence from the visual system suggests that while the refinement of feed-forward pathways may be nearly complete prenatally, feedback projections undergo extended periods of experience-dependent plasticity (Batardière et al. 2002) and thus remain susceptible to 


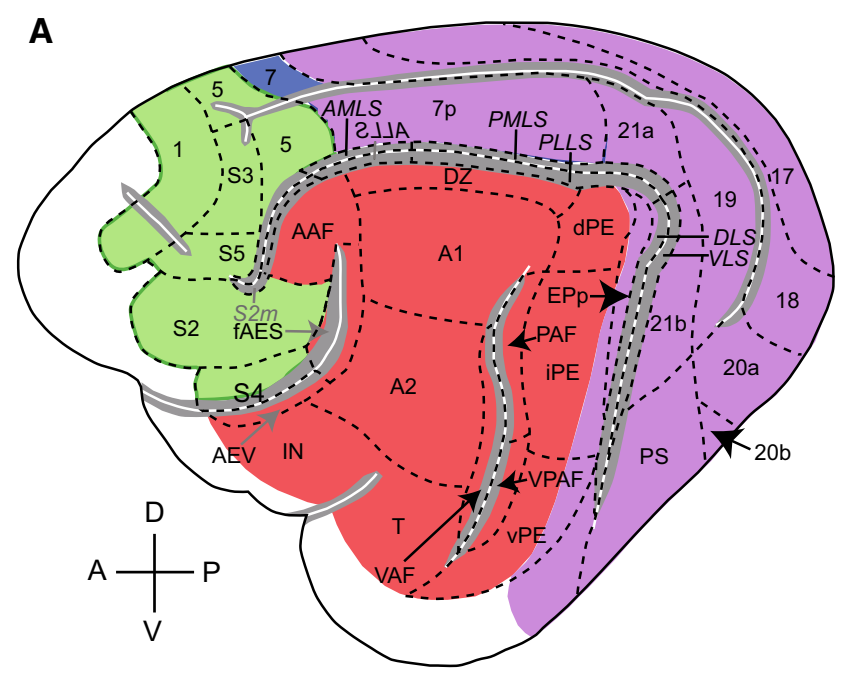

Fig. 1 Lateral (a) and medial (b) depictions of the left hemisphere of the cat brain. The auditory (red), visual (purple), somatomotor (green) and other (blue) cortical areas analysed in this study are highlighted. The bottom of each sulcus is represented by a white line and cortex

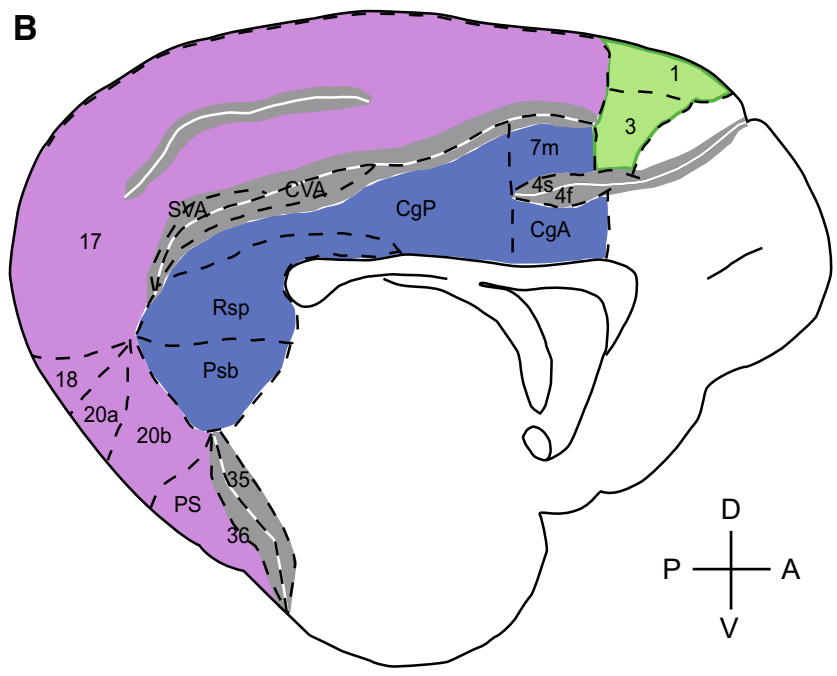

lying along the banks of sulci is grey. Dashed lines indicate cortical area borders. Dorso-ventral and antero-posterior axes are indicated at the bottom of each panel. For abbreviations, see list
Fig. 2 Lateral view of the left hemisphere of the cat brain with auditory cortical areas superimposed. The second auditory cortex (A2: blue) is shown to undergo an expansion following early deafness, while the primary auditory cortex (A1: red) occupies a smaller area following hearing loss. Dorsoventral and antero-posterior axes are indicated at bottom center Modified from the findings of Wong et al. (2014)

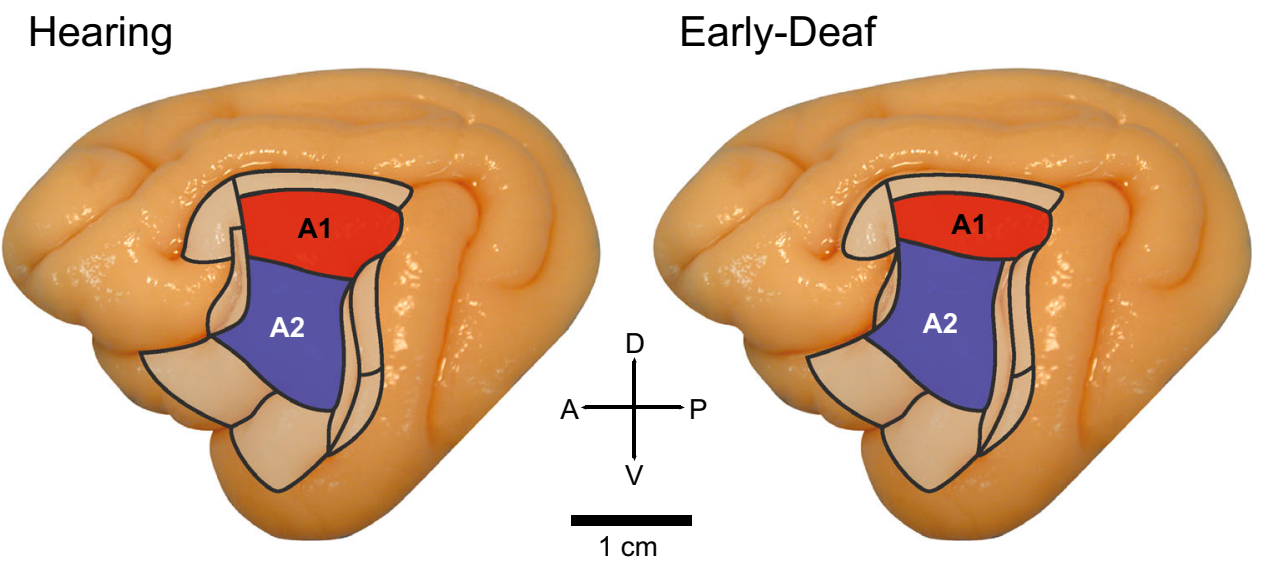

abnormal experience over longer periods. Since a significant proportion of inputs to A2 are projections that originate in higher level auditory cortical fields (Lee and Winer 2008c, 2011), the current study sought to determine whether differential patterns of projections might underlie changes in areal volume that occur following early- and late-onset hearing loss.

\section{Materials and methods}

The patterns of projections to the second auditory cortex (A2) were examined in 12 domestic short-hair cats obtained from a USDA licensed commercial breeding facility (Liberty Laboratories, Waverly, NY, USA). The experimental timeline for all three groups (normal hearing, early-onset deaf, and late-onset deaf) is provided in Fig. 3. Four animals were deafened shortly after the onset of hearing (mean: 22.3 days postnatal) to provide a model of early, prelingual deafness. An additional four animals were deafened no earlier than 9 months of age, providing a model of hearing loss following normal auditory development. In both cases, hearing loss was confirmed by the absence of click-evoked activity in the auditory brainstem response (ABR). Normal hearing animals exhibited the presence of an ABR signal at or below $20 \mathrm{~dB}$ nHL. All surgical and experimental procedures were conducted in accordance with the Canadian Council on Animal Care's Guide to the Care and Use of Experimental Animals (Olfert et al. 1993) and were approved by the University of Western Ontario Animal Use Subcommittee of the University Council on Animal Care. 


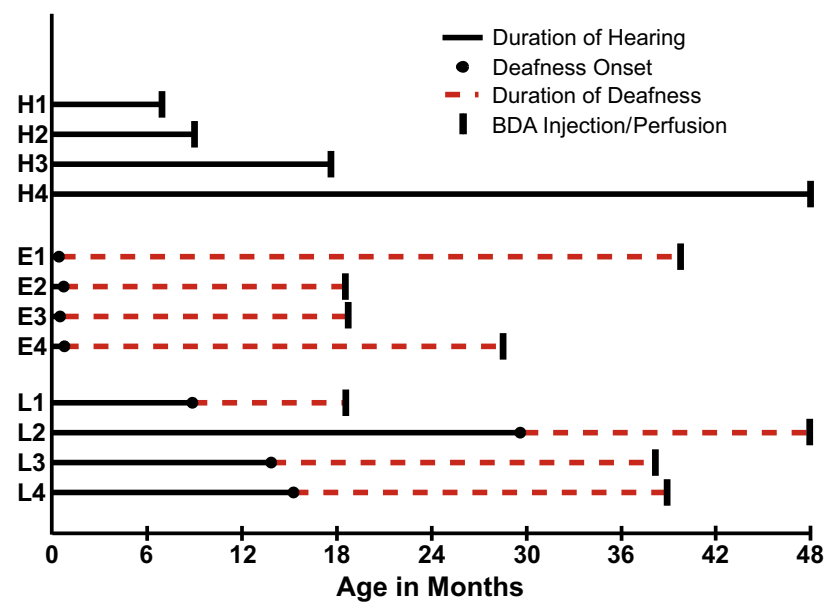

Fig. 3 Experimental timeline for the 12 cats examined. The duration of hearing is illustrated in solid black lines and deafness onset is indicated by solid black circles. The duration of deafness is represented by red dashed lines. After a period of deafness lasting at least 8 months, or after at least 7 months of age in hearing animals, retrograde BDA injections were made into A2 and animals were perfused (vertical lines)

\section{Deafening}

Permanent threshold shifts were induced ototoxically via co-administration of kanamycin and Edecrine ${ }^{\circledR}$ (ethacrynic acid; Valeant Pharmaceuticals, Laval, Quebec), a procedure that results in cochlear hair cell destruction and subsequent profound hearing loss (Xu et al. 1993). Anaesthesia was induced through the spontaneous inhalation of oxygen $(1 \mathrm{~L} / \mathrm{min})$ and isoflurane $(5 \%$ to effect for induction; $1.5-2 \%$ for maintenance). Baseline thresholds were measured, and ABRs were evaluated in response to clicks $(0.1 \mathrm{~ms}$ squarewave; range $0-80 \mathrm{~dB}$ nHL) to ensure normal auditory system function. Stimuli were presented through ER3A foam insert earbuds (Etymotic Research, Elk Grove Village, IL, USA), and electroencephalography (EEG) leads were placed subdermally behind the ears, with a reference lead at the vertex and a ground placed at the lower back. Kanamycin (300 mg/kg) was injected subcutaneously, and ethacrynic acid was infused (35-60 $\mathrm{mg} / \mathrm{kg}$ to effect) via intravenous catheter inserted into the cephalic vein of the forelimb. The ABR response to $80 \mathrm{~dB}$ click stimuli was measured continuously during infusion until the response was abolished. At this point, ethacrynic acid infusion was discontinued, and animals received an infusion of lactated Ringer's solution $(4 \mathrm{~mL} / \mathrm{kg})$. The indwelling catheter was then removed, and animals were allowed to recover from anaesthesia. Follow-up ABRs were measured approximately 3 months following deafening to confirm permanent threshold shift.

\section{Tracer deposits}

At least 8 months following the onset of deafness, or at least 7 months of age for hearing animals, injections of the retrograde tracer biotinylated dextran amine (BDA $3 \mathrm{~K}$ ) were made into either the right or left hemisphere. BDA $3 \mathrm{~K}$ is a robust retrograde tracer that is more sensitive than horseradish peroxidase (HRP), and which has been shown to label afferent projections more reliably than biocytin or neurobiotin (Lapper and Bolam 1991). Importantly, labelling with BDA has been shown to be stable with age, such that group differences cannot be attributed to the age of the animal at injection/perfusion (Rajakumar et al. 1993). Eighteen hours prior to surgery, cats were fasted and lightly anaesthetized with ketamine $(4 \mathrm{mg} / \mathrm{kg}$ i.m.) and dexdomitor $(0.05 \mathrm{mg} / \mathrm{kg}$ i.m.). The anti-inflammatory agent dexamethasone was administered $(0.05 \mathrm{mg} / \mathrm{kg}$ i.m.) and an indwelling catheter was placed in the cephalic vein for surgical anaesthesia. On the day of surgery, atropine $(0.02 \mathrm{mg} / \mathrm{kg}$ s.c.) was administered to minimize respiratory and alimentary secretions, along with acepromazine $(0.02 \mathrm{mg} / \mathrm{kg}$ s.c. $)$, dexamethasone $(0.5 \mathrm{mg} / \mathrm{kg}$ i.v. $)$, and buprenorphine $(0.01 \mathrm{mg} / \mathrm{kg}$ s.c.). Anaesthesia was induced using sodium pentobarbital $(25 \mathrm{mg} / \mathrm{kg}$ i.v. to effect). The topical anaesthetic Cetecaine was applied to the pharyngeal walls, and the animal was intubated. The head was shaved and stabilized in a stereotaxic apparatus, and the animal was prepared for surgery using aseptic procedures. Vital signals (respiratory rate, blood pressure, heart rate) were monitored throughout the procedure, and water-filled heating pads (Gaymar, Orchard Park, NY, USA) were employed to maintain a body temperature of $37^{\circ} \mathrm{C}$.

An incision was made along the midline of the skull, and the right or left temporalis muscle was reflected laterally. A craniotomy was opened which extended from the anterior ectosylvian sulcus (AES) to the posterior ectosylvian sulcus (PES) and from the suprasylvian sulcus to the posterior limit of the sylvian sulcus (Fig. 4). The dura was reflected laterally, and BDA [3000 MW, (10\%), Vector Laboratories Cat\# SP-1140 RRID:AB_2336249] was pressure injected (Nanoliter 2000, World Precision Instruments, Sarasota FL, USA) through a glass pipette. In order to ensure tracer spread throughout the cortical field, injections were made at three penetrations spanning the breadth of A2. At each penetration, $150 \mathrm{~nL}$ deposits were made at depths of 1200 and $500 \mu \mathrm{m}$ from the cortical surface to target deep and superficial layers, respectively. Following each injection, the pipette remained stationary for 3 minutes. When all six injections were complete, the brain was photographed to provide a record of injection sites (Fig. 4a). Following the closure of the craniotomy with acrylic and stainless steel skull screws, the animal was transitioned to isoflurane anaesthesia ( $1.5 \%$, spontaneously inhaled), lidocaine was 
Fig. 4 Injection locations in A2. a Shows the exposed left A2 following craniotomy and BDA injection (H2). The asterisks indicate the locations of the three penetrations. b Shows a lateral view of the cerebrum post-perfusion from the same animal. The perimeter of $\mathrm{A} 2$ is noted by a black dashed line. AES anterior ectosylvian sulcus, $P E S$ posterior ectosylvian sulcus, SSS suprasylvian sulcus, $S S$ sylvian sulcus
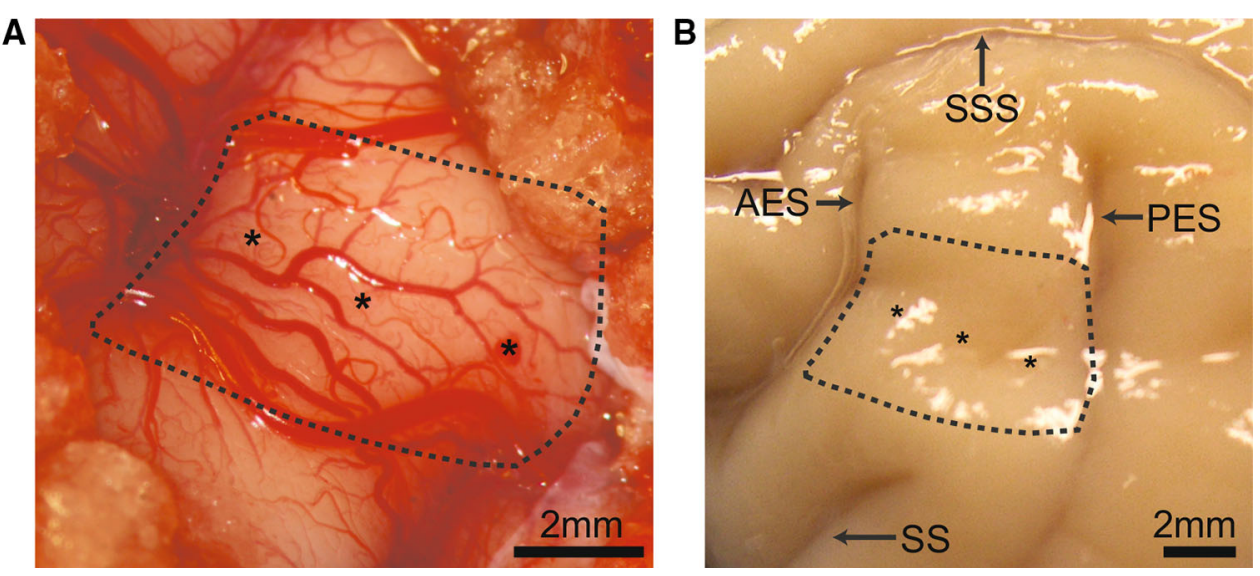

injected subcutaneously along the margins, and the incision was closed. When the swallowing reflex returned, the animal was extubated, the venous catheter was removed, and a bolus of Ringer's solution was given subcutaneously. Vital signals were monitored until the animal regained sternal recumbency, and the animal received buprenorphine $(0.01 \mathrm{mg} / \mathrm{kg} \mathrm{s.c.})$ every $6 \mathrm{~h}$ for the first $24 \mathrm{~h}$, and every $12 \mathrm{~h}$ for the subsequent $72 \mathrm{~h}$. Animals received dexamethasone every $24 \mathrm{~h}$ after surgery for 5 days $(0.05 \mathrm{mg} / \mathrm{kg}$ s.c. on postsurgical day one, decreasing by $0.01 \mathrm{mg} / \mathrm{kg}$ daily thereafter). In all cases, recovery was uneventful.

\section{Perfusion and tissue processing}

Ten to fourteen days following tracer injection, a catheter was placed in the cephalic vein and animals were deeply anaesthetized with sodium pentobarbital $(30 \mathrm{mg} / \mathrm{kg}$ i.v.). Heparin $(1 \mathrm{~mL}$; anticoagulant) and $1 \%$ sodium nitrite ( $1 \mathrm{~mL}$; vasodilator) were administered subcutaneously, and animals were intracardially perfused through the ascending aorta with $1 \mathrm{~L}$ of physiological saline, $2 \mathrm{~L}$ of fixative (4\% paraformaldehyde), and $2 \mathrm{~L}$ of cyroprotective solution (10\% sucrose). Each solution was buffered to a $\mathrm{pH}$ of 7.4 with $0.1 \mathrm{M}$ Sorenson's buffer and was infused at a rate of $100 \mathrm{~mL} / \mathrm{min}$. Following perfusion, the head was mounted in a stereotaxic frame, and the brain was exposed, photographed (Fig. 4b), and blocked in the coronal plane at Horsley-Clarke level A27 (Horsley and Clarke 1908). The brain was removed and immersed in a $30 \%$ sucrose solution until it sunk ( $\sim 1$ week) to provide cryoprotection for histological processing.

Each brain was frozen and sectioned in the coronal plane at a thickness of $60 \mu \mathrm{m}$ using a Leica CM $3050 \mathrm{~s}$ (Leica Microsystems, Nussloch, Germany) cryostat. A total of six series were collected at $360 \mu \mathrm{m}$ intervals: one immunohistochemically processed for the presence of BDA using the avidin-biotin-peroxidase method (Covance
Research Products Inc.) with nickel-cobalt intensification (Veenman et al. 1992); one processed using the monoclonal antibody SMI-32 (Covance Research Products Inc; Sternberger and Sternberger 1983) to assist with laminar and areal delineation; one processed for cytochrome oxidase (Payne and Lomber 1996) and another using cresyl violet stain for Nissl bodies to assist with cortical and thalamic delineation; and two series that served as spares to be processed as necessary. Each reacted series was mounted onto gelatin-coated slides, air-dried, cleared, and coverslipped.

\section{Data analysis}

A Nikon E600 microscope equipped with Nomarski DIC imaging and a DXM 1200 digital camera was used to visualize BDA-labeled neurons. Tissue and injection site outlines were created using a motorized stage controlled by Neurolucida software (RRID:nif-0000-10294). A comprehensive search paradigm embedded in Neurolucida was used to ensure complete sampling during quantification. Neurons were counted only if the entirety of the soma was labelled, minimizing artefacts of the reaction process and ensuring a conservative estimate of neuronal projections (Fig. 5). Neurons immediately surrounding the injection site were not counted to avoid the inclusion of artefactual labelling. Further, cells later determined to be located within A2 were eliminated from further analysis (i.e. were not included in the total number of labelled cells when determining the proportion of cells within a given cortical or thalamic area). The full thickness of each section was examined by inspecting focal levels throughout the $z$-plane.

Labelled neurons were then attributed to cortical and thalamic areas on an individual-animal basis using sulcal and gyral patterns along with cytoarchitectural landmarks. SMI-32 is a monoclonal antibody with a high affinity for a dephosphorylated epitope on the medium- and highmolecular-weight subunits of neurofilament proteins 


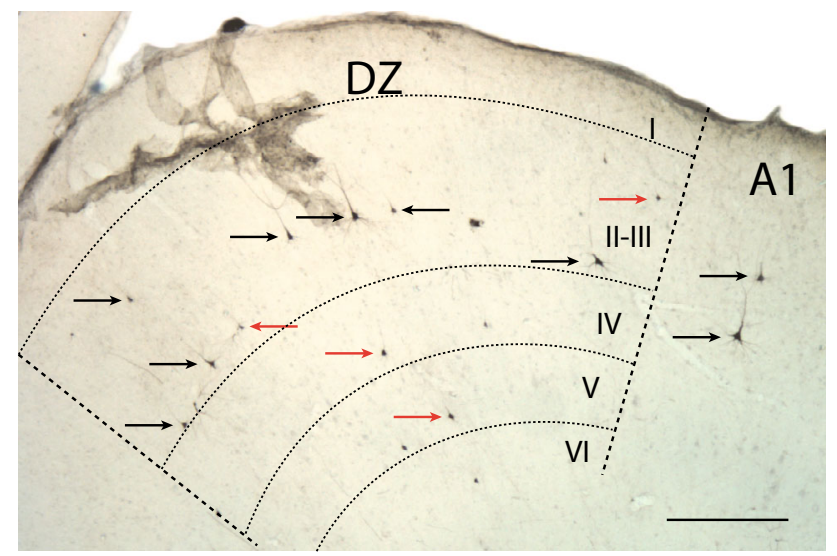

Fig. 5 Labelled neurons in the auditory cortex (dorsal zone and adjacent primary auditory cortex) following injection of BDA into A2. Black arrows indicate labelled neurons. In order to be counted, the nucleus had to be visible and the entirety of the somatic membrane needed to be present. Red arrows indicate neurons too faint to be counted or artefactual staining

(Sternberger and Sternberger 1983). Patterns of SMI-32 labelling differ by area in the visual and auditory cortex (van der Gucht et al. 2001; Mellott et al. 2010) as well as the thalamus (Bickford et al. 1998), and are preserved following hearing loss (Wong et al. 2014). Borders between auditory and somatosensory cortices are distinguished by a marked increase in SMI-32 reactivity (van der Gucht et al. 2001), and borders between somatosensory cortical fields are delineated using Nissl labelling profiles (Clascá et al. 1997). Borders between the posterior lateral suprasylvian areas (PLLS and PMLS) and the dorsal and ventral lateral suprasylvian areas (DLS and VLS, respectively) of visual cortex were placed on the lateral bank of the middle suprasylvian sulcus and the dorsal bank of the posterior limb of the suprasylvian sulcus, respectively (as per Palmer et al. 1978; Rauschecker et al. 1987). Neurons at the border between two cortical or thalamic areas were distributed equally to each of the two areas.

Complete labelling profiles for each of the three groups examined were contrasted to determine whether any significant differences in the patterns of projections exist. In order to simplify visual comparisons between groups, labelled neurons were plotted on standardized slices, with labelled cells repositioned to lie in the correct cortical areas. Separate analyses of variance were computed to determine whether group-level differences existed in the pattern of projections at the level of individual cortical and thalamic fields and at the level of modality of origin.

\section{Results}

\section{Injection sites and tracer spread}

Twelve cats received injections of the retrograde neuroanatomical tracer BDA $3 \mathrm{~K}$ throughout all six layers of the second auditory cortex (A2) to ensure uptake at axon terminals. Three injection tracks were placed along a line from the anterior to posterior extents of the field, while ensuring that the spread of BDA was restricted to the field of interest. In all cases, tracer spread was observed across all cortical layers, with no evidence of tracer deposits in any cortical area beyond A2 (Figs. 6, 7).

\section{Summary of projections in hearing animals and comparison to existing literature}

The patterns of thalamocortical (Lee and Winer 2008a) and corticocortical (Lee and Winer 2008c) projections to A2 have been previously examined. However, these studies quantified only those projections arising from auditory thalamic and cortical regions in normal hearing animals. In the current study, neurons labelled by an injection of BDA into A2 were assigned to cortical and thalamic areas of origin across the entire hemisphere ipsilateral to the injection site. These cells were then counted and converted to a proportion of total labelled cells on an individual animal basis to allow for comparisons across animals despite variability in tracer uptake or immunohistochemical visualization of labelled cells. An example labelling profile from a normal hearing animal is presented in Fig. 8. In accordance with Lee and Winer (2008a), we found that thalamic projections to $\mathrm{A} 2$ arose principally from the dorsal division of the medial geniculate body (MGBd), with a smaller number of labelled cells observed in the medial (MGBm) and ventral divisions (MGBv; Fig. 9). However, the pattern of projections arising from auditory cortical regions differs considerably from previous work (Lee and Winer 2008c); while the predominant inputs to A2 were previously shown to originate in the ventral auditory field (VAF), and in the dorsal and intermediate divisions of the posterior ectosylvian gyrus (dPE and iPE, respectfully), the current study suggests that the principle input to A2 arises from the auditory field of the anterior ectosylvian sulcus (fAES), with a smaller number of labelled cells observed in each of the remaining 11 auditory cortical areas (Fig. 10). Interestingly, A2 was also recently shown to be one of the principle inputs to fAES (Meredith et al. 2016), a reciprocal connection that Lee and Winer 
Fig. 6 Photomicrographs of coronal sections through A2 showing a representative injection site (E4). a Shows a section reacted for BDA and demonstrating the injection spread. Tracer was limited to the boundaries of $\mathrm{A} 2$, and spanned all six layers of neocortex. The section in $\mathbf{b}$ was stained with Nissl, and was used along with SMI-32 and CO (not shown) to identify cortical and thalamic borders
A

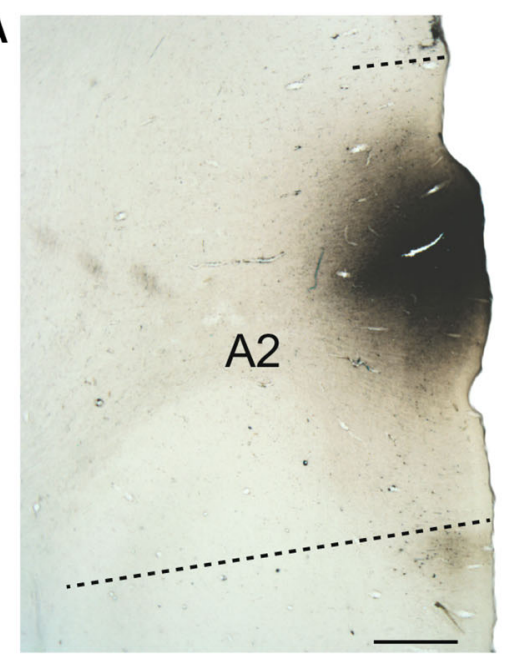

B

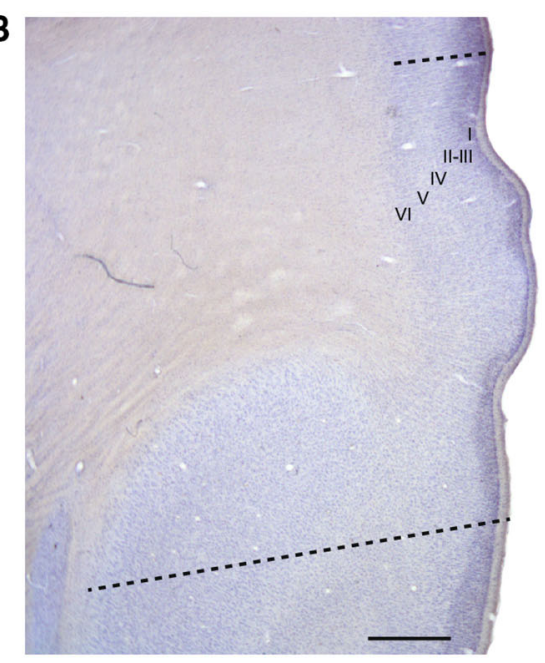

(2008c) failed to observe. The source of this discrepancy is unclear; the current study defined areal borders using SMI32 staining profiles rather than the Nissl-stained sections used by Lee and Winer; in our hands SMI-32 provides much more clearly defined cortical boundaries which may have influenced the areas to which labelled cells were assigned. Because the current study quantified only those labelled cortical neurons ipsilateral to the injection site, we cannot comment on commissural projections to A2, which have previously been shown to originate overwhelmingly from the contralateral A2 (Lee and Winer 2008b).

\section{Crossmodal connectivity}

The current study is the first to quantify projections to A2 in the cat that arise from non-auditory cortical areas. In normal hearing animals, projections from visual cortical regions arose overwhelmingly from the anterior ectosylvian visual area (AEV) with fewer cells observed in area $21 \mathrm{~b}$ and in the posterolateral lateral suprasylvian visual area (PLLS; Fig. 11). Small somatosensory projections were observed in the second, second medial, and fourth somatosensory areas (S2, S2m, and S4, respectively; Fig. 12). Finally, a small but significant number of labelled cells were observed in Area 36 of the perirhinal cortex (Fig. 13), part of the principle route by which information is passed between the cortex and the hippocampi.

\section{Effects of hearing loss}

In addition to quantifying non-auditory projections to A2, this study sought to measure changes in thalamocortical and corticocortical connectivity that arise as a consequence of early- and late-onset deafness. Representative labelling profiles for early- and late-deaf animals are presented in Figs. 14 and 15, respectively. Across modalities, the mean proportions of labelled cells in a given cortical or thalamic region were strikingly similar to those values observed in normal hearing animals. Some very small differences were observed between early-deaf and normal hearing animals [e.g. increased projections from the visual cortical anterolateral lateral suprasylvian area (ALLS; Fig. 11) and second somatosensory area (S2; Fig. 12)]; however, a mixed model analysis of variance with area of origin as a withinsubjects factor and hearing status as a between-subjects factor revealed no significant interactions between group and any of the regions examined $[F(78,351)=0.949$, $p=0.60]$.

\section{Summary-level projections to A2}

In order to quantify the projections to A2 by modality of origin, labelled cells were classified as arising from auditory, visual, somatomotor, or other cortical regions of the brain (as outlined in Fig. 1). Projections arising from auditory (MGBd, MGBm, MGBv), visual (PO, SGM), and multisensory (LP) thalamic nuclei were grouped to represent the thalamic input to A2. For each animal, these summary values were divided by the total number of labelled cells in the brain (ipsilateral to the injection site, after subtracting those labelled cells located within the borders of A2 itself), and the mean proportion of cells arising from each cortical/thalamic region was then calculated. Figure 16 illustrates these summary-level estimates for each group. Across all groups examined, the majority of projections to A2 arise from auditory cortical regions (NH: 56.3\%; ED: 59.3\%; LD 68.6\%), with an additional large thalamic input (NH: 29.3\%; ED: 24.3\%; LD $19.8 \%$ ). However, in each group more than $10 \%$ of the cells labelled by an injection in A2 were located in nonauditory cortical areas, with the majority of these projections originating in visual cortex $(\mathrm{NH}$ : 9.5\%; ED: 11.3\%; 
Fig. 7 Illustration of tracer spread for each animal included in the present study. Individual A2 borders (dashed lines) and tracer spreads (red) have been plotted on four standardized sections to allow for comparison between animals and experimental groups. Inset: lateral view of the cat cortex. Solid lines show the approximate locations of the sections shown. Gray shaded area indicates the location of A2
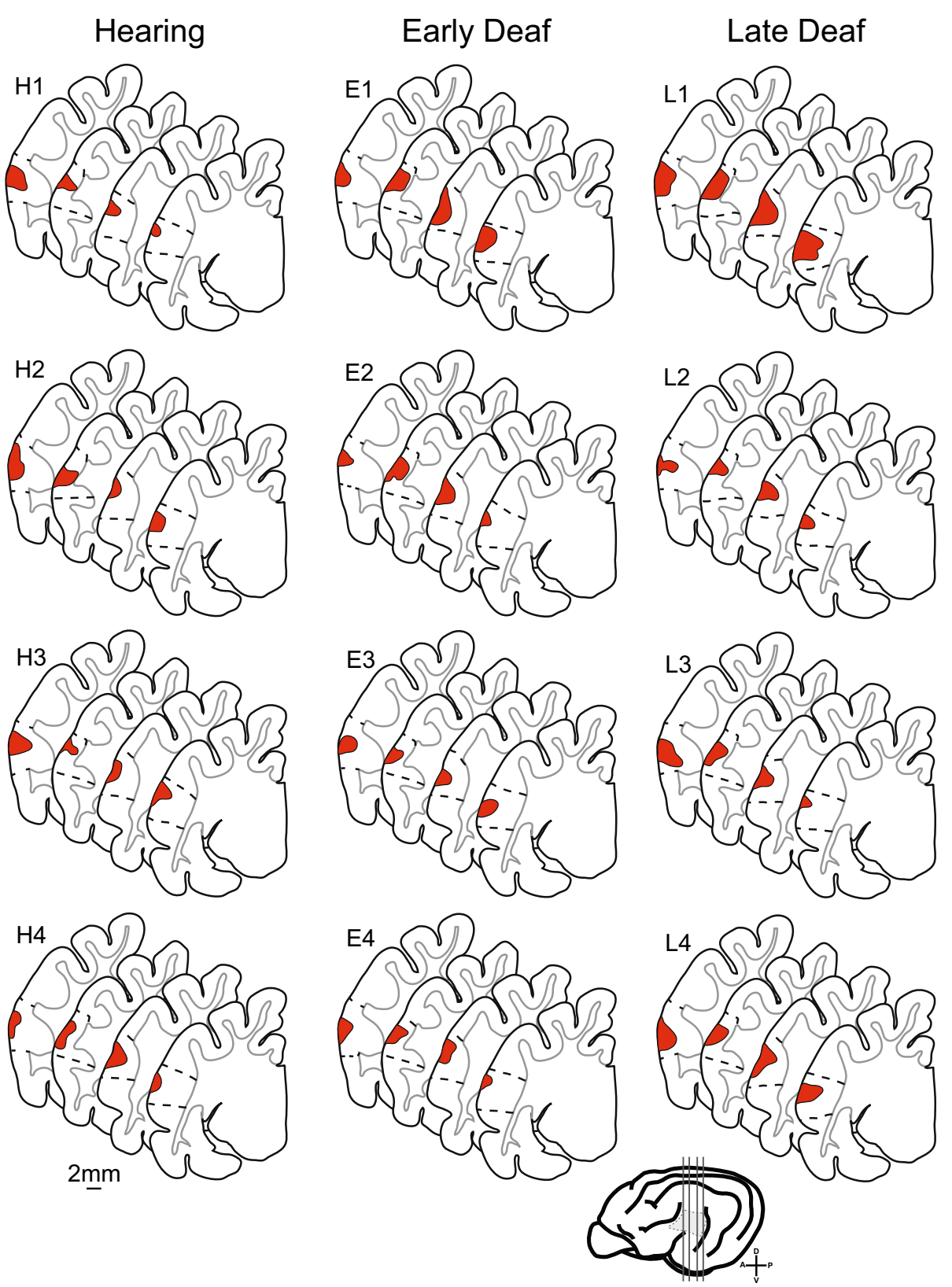

tonotopic organization (Merzenich et al. 1975; Reale and Imig 1980). Moreover, A2 neurons appear more broadly tuned (Imig and Reale 1980) and less sensitive (Schreiner and Cyander 1984) than those in the primary auditory cortex. While a number of functional assessments have been undertaken, few studies have examined the anatomical connectivity to A2. Lee and Winer provided detailed descriptions of thalamocortical (2008a), commissural (2008b), and corticocortical (2008c) connectivity; however, their work was confined to auditory brain regions. In contrast to their findings, the current study provides evidence for a robust projection arising from the auditory field of the anterior ectosylvian sulcus (fAES). Interestingly, a recent study by Meredith et al. (2016) also described A2 as 


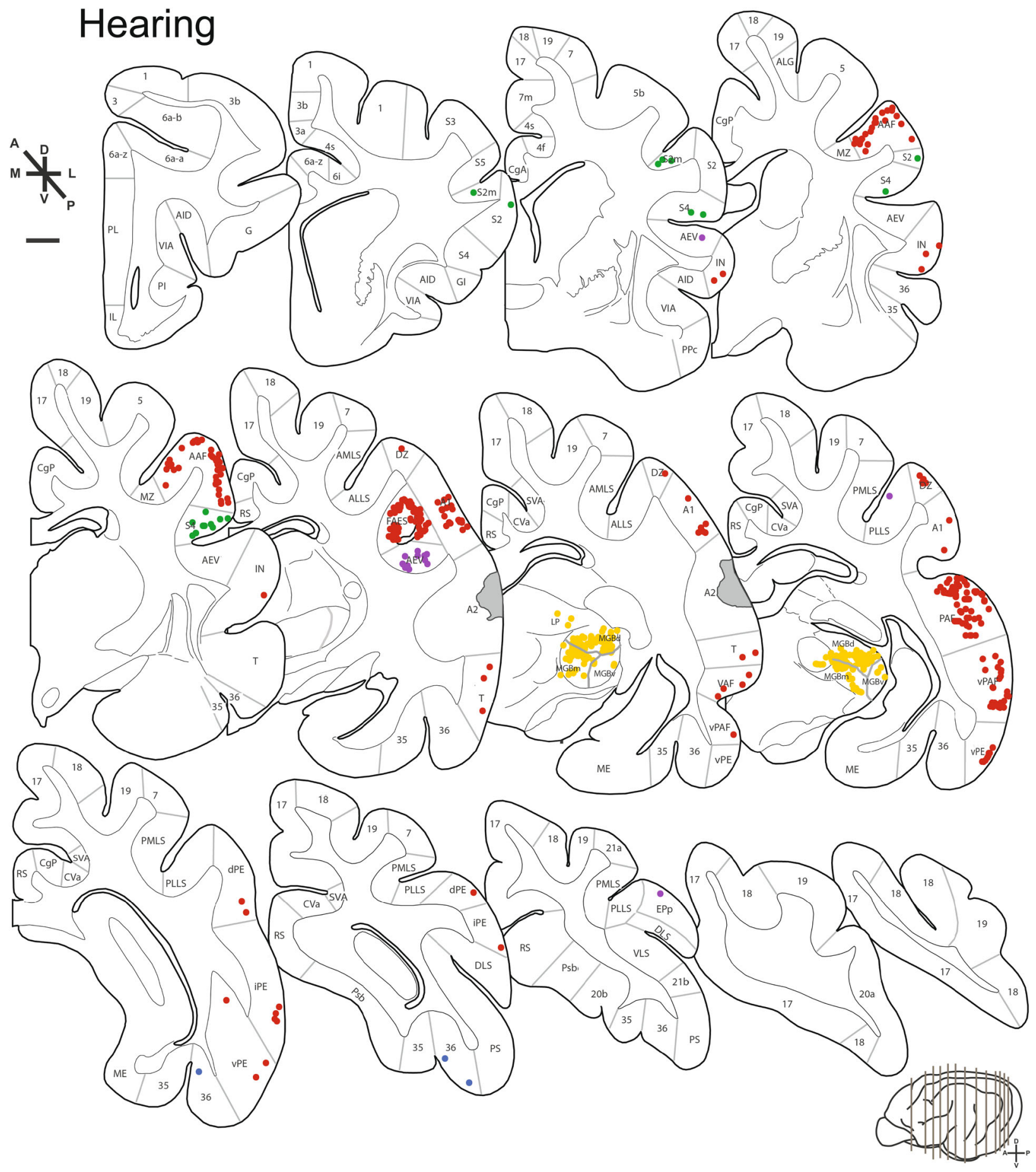

Fig. 8 Representative distribution of labelled neurons projecting to the second auditory cortex of a hearing cat (H4). Colour-coded dots represent labelled neurons from auditory (red), visual (purple), somatomotor (green), and other (blue) cortical areas, as well as

the principle auditory cortical input to fAES-another projection that was not previously documented. In the cat, fAES is primarily responsive to auditory stimuli, but contains a subset of cells that respond to multisensory stimulation (Meredith et al. 2011). fAES is also a major source projections from auditory thalamus (yellow). Injection spread in A2 is shown in gray. Bottom right: a lateral brain view showing the selected levels from which the mapped coronal sections were taken

of auditory cortical input to the superior colliculi (Meredith and Clemo 1989; Chabot et al. 2013; Butler et al. 2016b) and thus is expected to contribute to orienting and localization behaviours (Malhotra et al. 2004; Meredith et al. 2011). Interestingly, A2 is considered to be part of the 

the mean proportion of labelled neurons projecting from thalamic nuclei. The $y$-axis represents the percent of all labelled neurons ipsilateral to the injection site. Thalamic nuclei projecting to $\mathrm{A} 2$ are listed along the $x$-axis. Error bars show the standard error of the mean
Fig. 9 Histogram illustrating

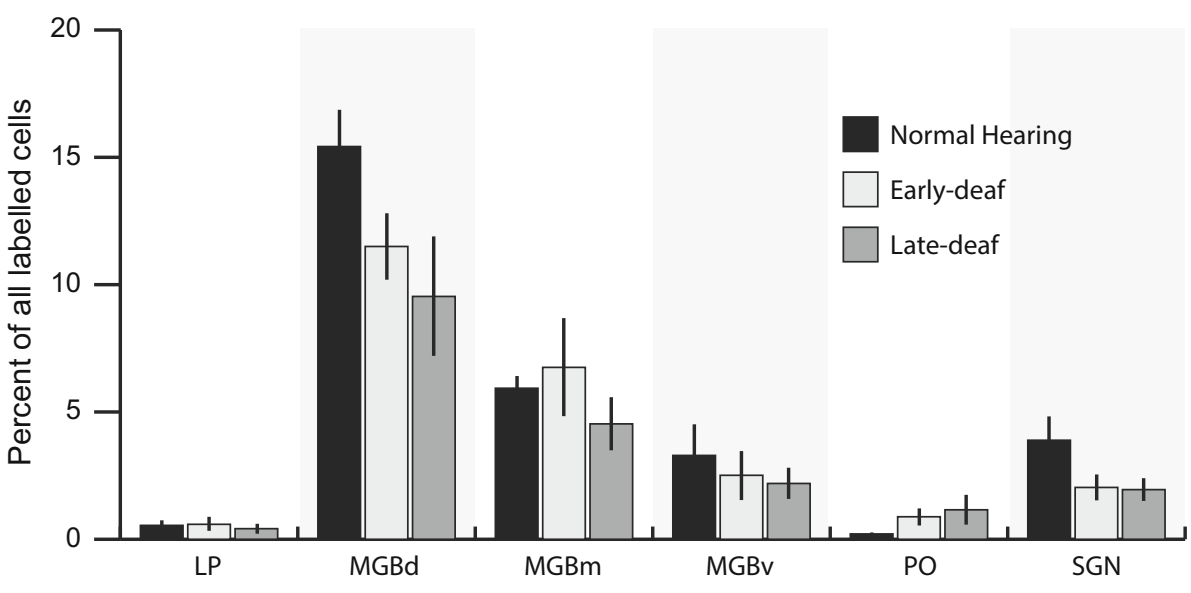

Fig. 10 Histogram illustrating the mean proportion of labelled neurons projecting from areas in the ipsilateral auditory cortex. The $y$-axis represents the percent of all labelled neurons ipsilateral to the injection site. Ipsilateral auditory areas projecting to $\mathrm{A} 2$ are listed along the $x$-axis. Error bars show the standard error of the mean
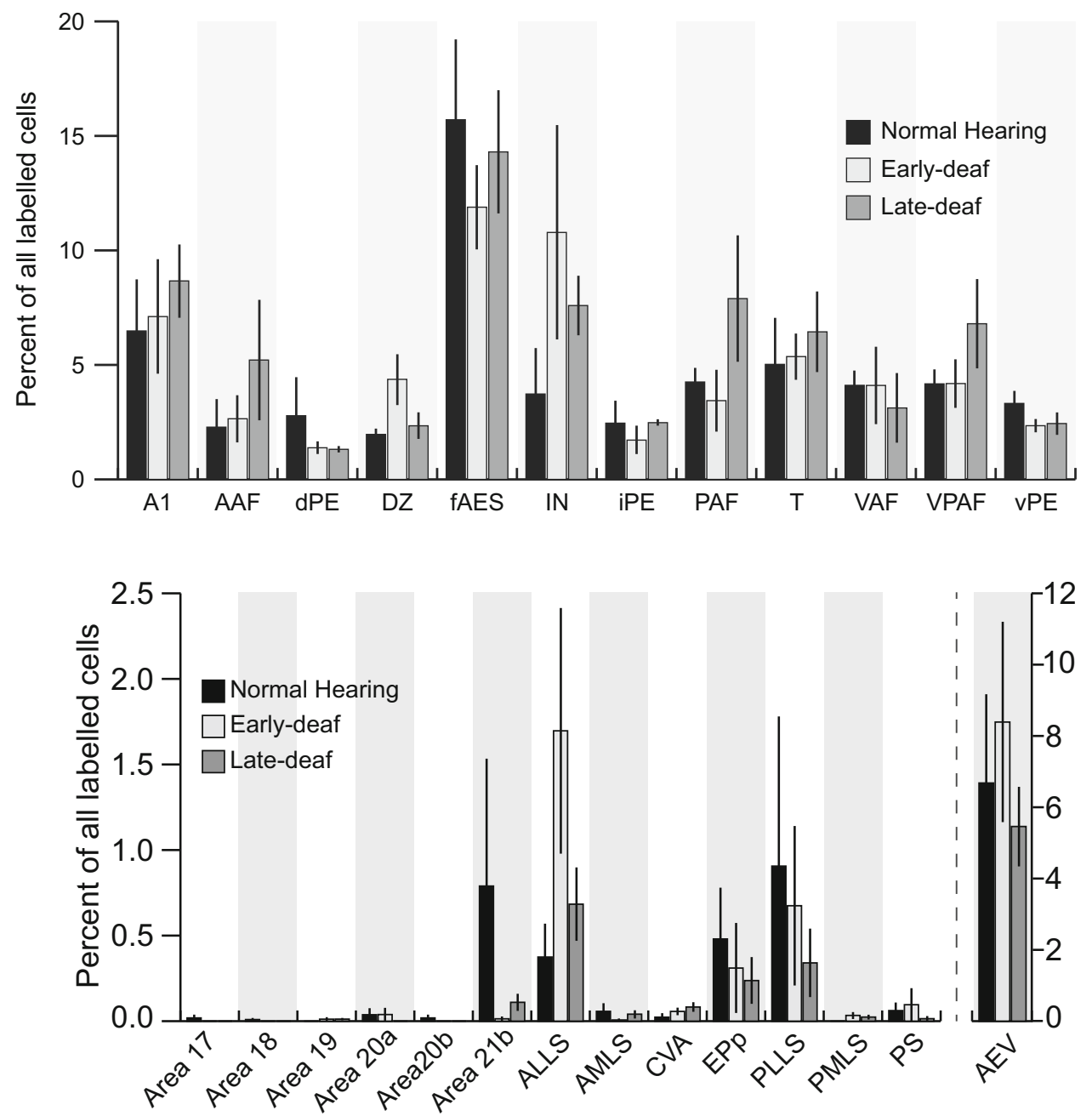

Fig. 11 Histogram illustrating the mean proportion of labelled neurons projecting from areas in the ipsilateral visual cortex. The $y$-axes represent the percent of all labelled neurons ipsilateral to the injection site. Ipsilateral visual areas projecting to $\mathrm{A} 2$ are listed along the $x$-axis. Error bars show the standard error of the mean auditory ventral pathway, contributing to object identification, while fAES has been placed within the dorsal "where" pathway (e.g. Lee and Winer 2011); this classification is reinforced by behavioural evidence that reversible deactivation of fAES significantly impairs sound localization in the contralateral hemifield, while deactivating A2 has no measureable effect (Malhotra et al. 2004). However, this functional dissociation is in contrast to the strong anatomical connectivity described above, and electrophysiological evidence that individual units in A2 and fAES show strikingly similar tuning both for locations along the azimuth (Middlebrooks et al. 1998), and for 


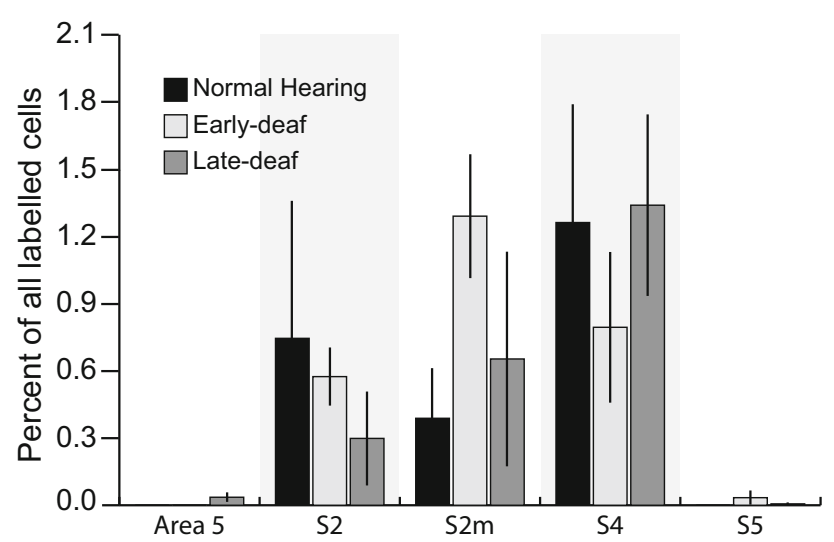

Fig. 12 Histogram illustrating the mean proportion of labelled neurons projecting from areas in the ipsilateral somatosensory cortex. The $y$-axis represents the percent of all labelled neurons ipsilateral to the injection site. Ipsilateral somatosensory areas projecting to PAF are listed along the $x$-axis. Error bars show the standard error of the mean

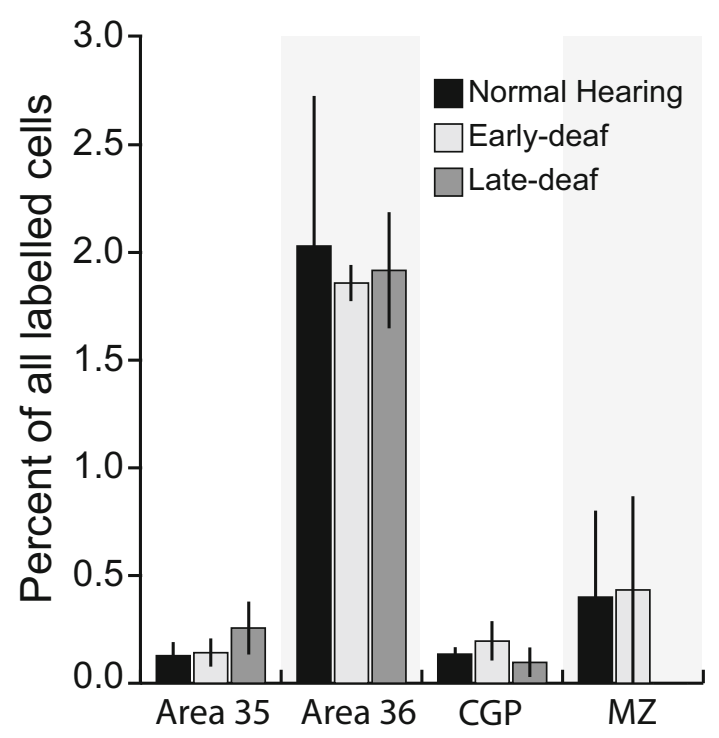

Fig. 13 Histogram illustrating the mean proportion of labelled neurons projecting from other ipsilateral cortical areas (those not regarded as visual-, auditory-, or somatosensory-dominant in nature). The $y$-axis represents the percent of all labelled neurons ipsilateral to the injection site. Ipsilateral cortical areas projecting to A2 are listed along the $x$-axis. Error bars show the standard error of the mean

stimulus elevation (Xu et al. 1998). This may reflect a significant point of intersection between the dorsal and ventral auditory streams where information about the location of an object is used to inform that identity of the sound source (e.g. a rustling sound originating from above the head may suggest a bird, while one originating from below may more likely be a mouse), and vice versa. Alternatively, A2 may play a more direct role in sound localization that previous work failed to capture due to issues with sensitivity or stimulus design.
In addition to quantifying connectivity within auditory cortex, the current study revealed that $14.5 \%$ of the cells labelled by retrograde BDA injection in A2 are located outside of auditory cortical and thalamic areas, with the largest single projection arising from the anterior ectosylvian visual area (AEV). AEV is a nonretinotopic, featuremapping area in which cells sensitive to motion direction and/or motion contrast functionally relate the motor and limbic systems, contributing to orienting behaviour (Scannell et al. 1996). The second largest visual input to A2 arose from PLLS, an area that shows directionally sensitive responses to high-velocity moving visual stimuli (von Grünau et al. 1987), and in which bimodal and subthreshold multisensory activity has been recorded (Clemo et al. 2008). Reciprocal connections from A2 to PLLS have also been documented (Clemo et al. 2008); moreover, dense connectivity between PLLS and cortical regions along the anterior ectosylvian sulcus (including fAES and AEV) has been described (Scannell et al. 1995). These auditory and visual cortical projections (Fig. 17) collectively suggest a role for A2 in the perception of, and orientation toward, complex stimuli. In accordance with its placement within the ventral stream, it is possible that A2 is primarily involved in sound identification, but incorporates multimodal information regarding the location and motion of stimuli to inform these percepts. Alternatively, it remains possible that A2 instead contributes to dorsal stream processing; the anatomical hierarchy constructed previously (Lee and Winer 2011) did not examine extramodal inputs to this field, nor did it capture large-scale reciprocal connectivity between A2 and high-level dorsal stream areas like fAES (Meredith et al. 2016; this study). Moreover, while Lee and Winer place primary auditory cortex (A1; dorsal stream) and A2 in distinct pathways based on weak connectivity between the regions, there is electrophysiological evidence of robust bilateral interactions between the two areas (Carrasco and Lomber 2010). Finally, the absence of localization deficits following A2 deactivation was based on a single task (localization in the azimuth; Malhotra et al. 2004) such that the direct contribution of A2 may not have been explicitly examined. It should be noted that electrophysiological data were collected from the hemisphere contralateral to the injection site and thus, only ipsilateral projections were characterized in the current study. Moreover, our analysis was limited to cortical and thalamic inputs and thus did not quantify inputs arising from lower level brain structures (but see Rouiller et al. 1989).

\section{Experience-dependent plasticity}

In addition to examining non-auditory cortical connectivity to the A2 in hearing animals, the current study sought to 


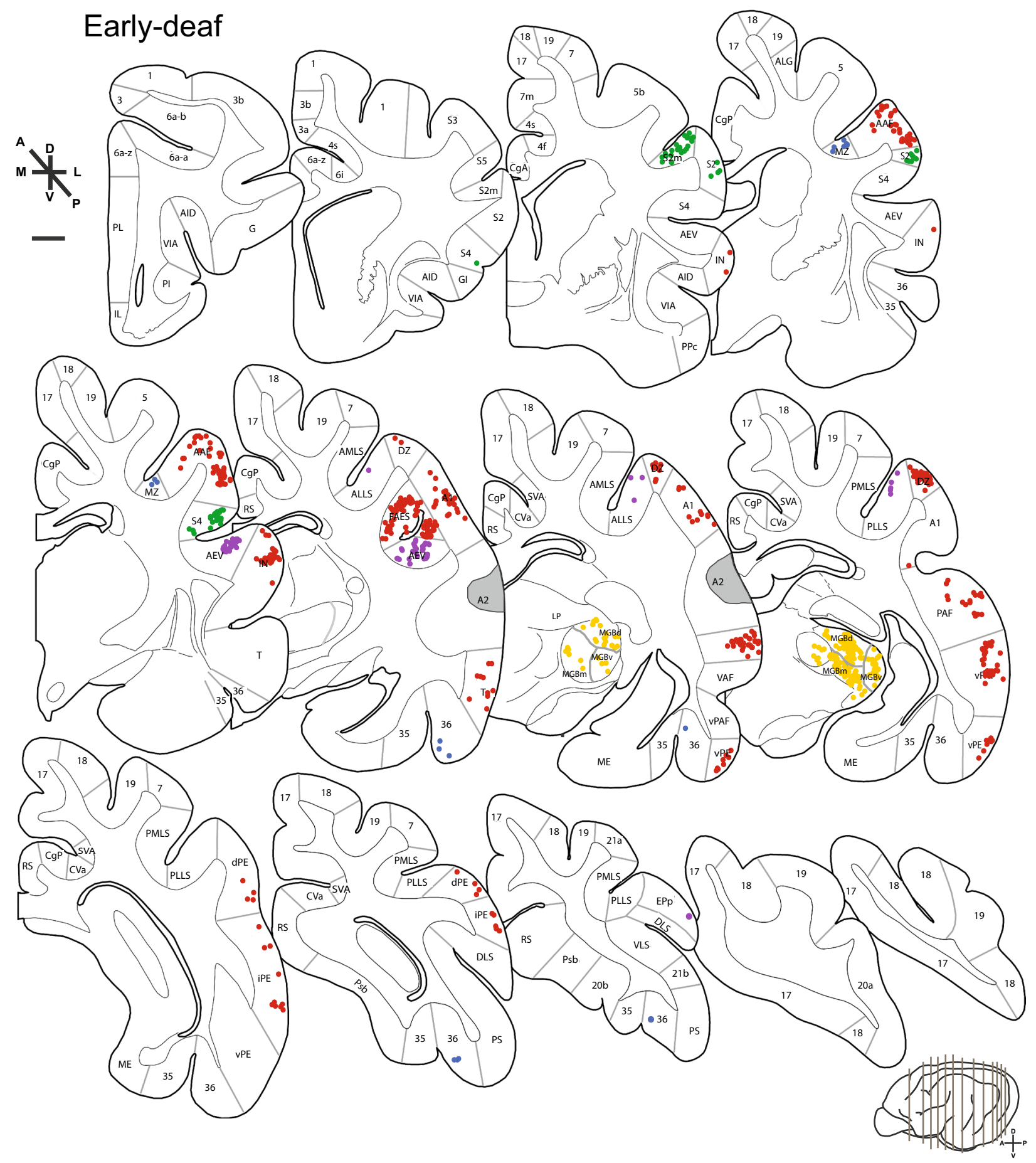

Fig. 14 Representative distribution of labelled neurons projecting to the second auditory cortex of an early-deaf cat (E1). Colour-coded dots represent labelled neurons from auditory (red), visual (purple), somatomotor (green), and other (blue) cortical areas, as well as

determine whether patterns of projections to this area are altered by the onset of hearing loss. The anatomical and functional consequences of sensory loss have been topics of interest across sensory modalities and models (e.g. Merzenich et al. 1984; Karlen et al. 2006; Charbonneau projections from auditory thalamus (yellow). Injection spread in A2 is shown in grey. Bottom right: a lateral brain view showing the selected levels from which the mapped coronal sections were taken

et al. 2012). However, it remains a challenge to draw overarching conclusions regarding the mechanisms underlying crossmodal plasticity from this body of work, due in part to apparent differences between species and sensory systems (see recent reviews by Mezzera and Lopez- 


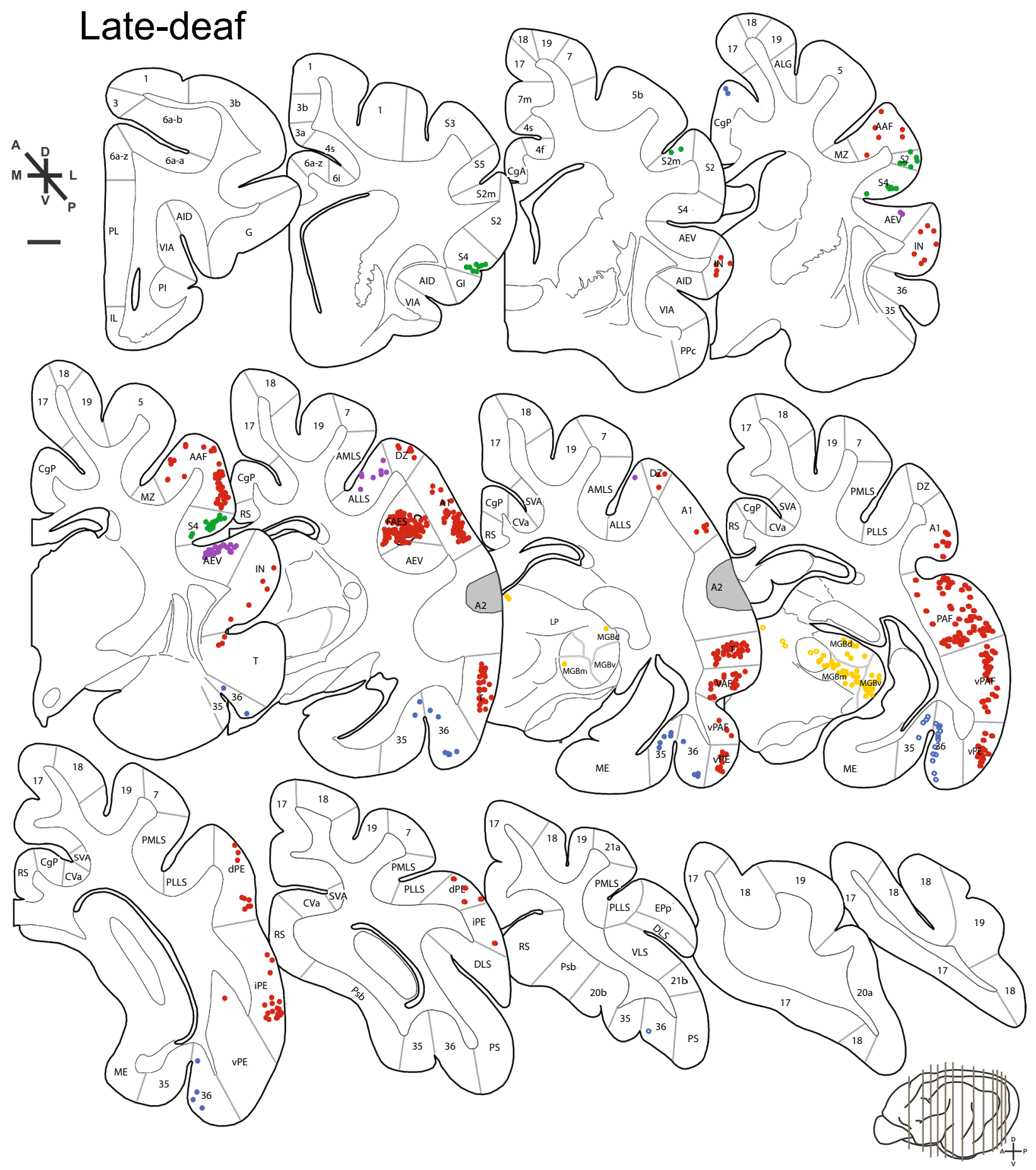

Fig. 15 Representative distribution of labelled neurons projecting to the second auditory cortex of a late-deaf cat (H1). Colour-coded dots represent labelled neurons from auditory (red), visual (purple), somatomotor (green), and other (blue) cortical areas, as well as

Bendito 2016; Meredith and Lomber 2017). It is, however, well established that the absence of auditory input results in functional reorganization of auditory cortical areas in both humans (Neville et al. 1983; Levänen et al. 1998; Finney projections from auditory thalamus (yellow). Injection spread in A2 is shown in grey. Bottom right: a lateral brain view showing the selected levels from which the mapped coronal sections were taken

et al. 2001; Lee et al. 2001; Levänen and Hamdorf 2001; Lambertz et al. 2005; Pekkola et al. 2005; Bhattacharjee et al. 2010; Karns et al. 2012) and animal models (Hunt et al. 2006; Allman et al. 2009; Lomber et al. 2010, 2011; 


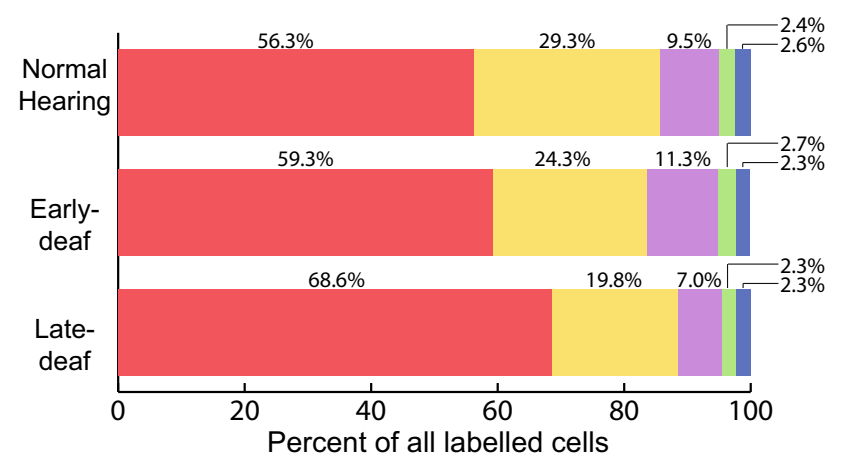

auditory Thalamic $\square$ Visual $\square$ Somatomotor $\square$ Other

Fig. 16 Bar graph illustrating modality-level projections to the second auditory cortex of normal hearing, early-deaf, and late-deaf cats. Projections arising from the thalamus (yellow) and auditory (red), visual (purple), somatomotor (green), and other cortical areas (blue) are plotted relative to the total number of labelled cells ipsilateral to the injection site

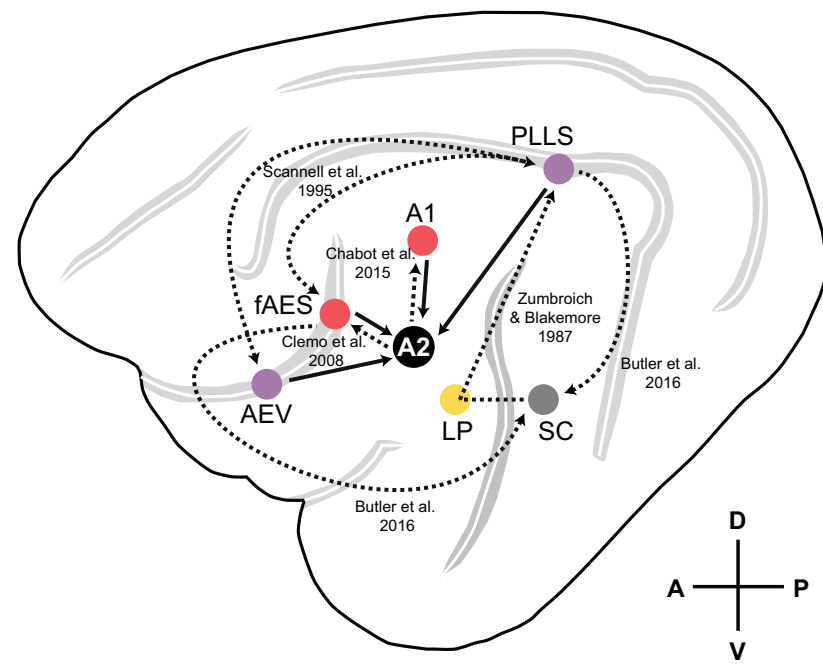

Fig. 17 Most substantive auditory and visual inputs to the second auditory cortex. The two largest inputs to A2 from each modality documented in the current study are represented by solid arrows. Dotted arrows represent connectivity between these areas that has been documented by previous anatomical work. Dorso-ventral and antero-posterior axes are indicated at bottom right

Meredith et al. 2011; Meredith and Lomber 2011). While these studies have not yet provided evidence of crossmodal reorganization in A2, there are reasons to believe this field might be altered by the onset of hearing loss. For example, the functional organization of A2 has been shown to be highly variable between animals; Schreiner and Cyander (1984) note that this variability (which exceeds that observed in adjacent cortical fields like A1) suggests that A2 is more likely to undergo experience-dependent plasticity than less variable fields. Moreover, A2 was shown to undergo an expansion in areal volume following the early onset of hearing loss while the majority of areas were either reduced in size or were unchanged (Wong et al. 2014). Despite this, the current study found no evidence of a significant change in the pattern of projections to A2 following the onset of hearing loss. Across modalities, the number of labelled cells in a given cortical or thalamic area remained the same, even when deafness coincided with the onset of hearing. Moreover, the relative contributions across sensory modalities were stable across groups. It should be noted that in order to ensure injections were confined within the borders of $\mathrm{A} 2$, the specific pattern of projections to the border areas of $\mathrm{A} 2$ was not examined in the current study and remains an area of interest for future exploration. Importantly, the brief period of hearing experience that occurs between canal opening and deafening in early-deaf animals is expected to have minimal impact given evidence from previous comparisons between early-deaf and congenitally deaf animals (Butler et al. 2017).

It is worth noting that the absence of change in the number of crossmodal projections does not preclude functional reorganization in A2. For example, both the posterior auditory field (PAF; Lomber et al. 2010) and fAES (Meredith et al. 2011) have been shown to contribute to enhanced peripheral visual perception in deaf cats (Lomber et al. 2010), despite recent studies that failed to document any substantial changes in the pattern of crossmodal connectivity to these areas in deaf animals relative to normal hearing controls (Meredith et al. 2016; Butler et al. 2016a, 2017). Interestingly, it has also been noted that much of the anatomical connectivity thought to depend upon the onset of normal function in the visual cortex [e.g. the establishment of retinotopic maps in V1 (Striem-Amit et al. 2015)] is preserved in the congenitally blind, despite evidence of crossmodal reorganization (e.g. Sadato et al. 2002; Amedi et al. 2003). These apparent disparities suggest that, rather than arising from large-scale differences in cortical connectivity, functional reorganization may be the result of synapse-level structural changes to existing connections or the unmasking/enhancement of synaptic activity that normally provides subthreshold crossmodal input. Some evidence for this hypothesis was recently provided by Clemo et al. (2016), who demonstrated that spine density of neurons in fAES is increased in deaf animals compared to normal hearing controls. Interestingly, this difference was shown to be limited to dendrites in supragranular neurons, suggesting a role in altered corticocortical communication. This occurred in the absence of change in overall connectivity to this cortical region (Meredith et al. 2016). Moreover, a similar increase in the spine density of supragranular neurons was recently identified in primary auditory cortex (Clemo et al. 2017). While the current study was not designed to test synapselevel hypotheses, future anatomical and functional 
examinations in A2 could help resolve the pattern of change that underlies the expansion in fractional volume observed in A2 and may inform how crossmodal reorganization occurs following sensory loss.

\section{Conclusions}

Following an injection of BDA into the second auditory cortex, labelled neurons throughout the brain were quantified, and the pattern of projections was compared between normal hearing animals and those with early- and lateonset deafness. In the normal hearing brain, the primary auditory and visual areas projecting to A2 suggest a role in orienting to stimuli in the multisensory environment. Importantly, this pattern of projections is maintained following the onset of hearing loss, suggesting that (1) the absence of sound-evoked neural activity does not initiate large-scale crossmodal reorganization in this field, and (2) the anatomical connectivity that underlies normal hearing may support the resumption of sound processing following cochlear implantation.

Acknowledgements The authors would like to thank Pam Nixon for technical and surgical assistance. Thanks also to Benson Li, Chris Lee, and Kevin Ly for assistance with tissue processing. Funding for this work was provided by the Natural Sciences and Engineering Research Council of Canada, the Canadian Institutes of Health Research, and the Canada Foundation for Innovation.

\section{Compliance with ethical standards}

Funding Funding for this work was provided by the Natural Sciences and Engineering Research Council of Canada, the Canadian Institutes of Health Research, and the Canada Foundation for Innovation.

Conflict of interest The authors declare that they have no conflict of interest.

Ethical approval All surgical and experimental procedures were conducted in accordance with the Canadian Council on Animal Care's Guide to the Care and Use of Experimental Animals (Olfert et al. 1993) and were approved by the University of Western Ontario Animal Use Subcommittee of the University Council on Animal Care.

\section{References}

Allman BL, Keniston LP, Meredith MA (2009) Adult deafness induces somatosensory conversion of ferret auditory cortex. Proc Natl Acad Sci USA 106:5925-5930

Amedi A, Raz N, Malach R, Zohary E (2003) Early 'visual' cortex activation correlates with superior verbal memory performance in the blind. Nat Neurosci 6:758-766

Auer ET, Bernstein LE, Sungkarat W, Singh M (2007) Vibrotactile activation of the auditory cortices in deaf versus hearing adults. NeuroReport 18:645-658

Batardière A, Barone P, Knoblauch K, Giroud P, Berland M, Dumas AM, Kennedy H (2002) Early specification of the hierarchical organization of visual cortical areas in the macaque monkey. Cereb Cortex 12:453-565

Bhattacharjee A, Ye AJ, Lisak JA, Vargas MG, Goldreich D (2010) Vibrotactile masking experiments reveal accelerated somatosensory processing in congenitally blind braille readers. J Neurosci 30:14288-14298

Bickford MA, Guido W, Godwin DW (1998) Neurofilament proteins in Y-cells of the cat lateral geniculate nucleus: normal expression and alteration with visual deprivation. J Neurosci 18:6549-6557

Butler BE, Chabot N, Lomber SG (2016a) Quantifying and comparing the pattern of thalamic and cortical projections to the posterior auditory field in hearing and deaf cats. J Comp Neurol 524:3042-3063

Butler BE, Chabot N, Lomber SG (2016b) A quantitative comparison of the hemispheric, areal, and laminar origins of sensory and motor cortical projections to the superior colliculus of the cat. J Comp Neurol 524:2623-2642

Butler BE, Chabot N, Kral A, Lomber SG (2017) Origins of thalamic and cortical projections to the posterior auditory field in congenitally deaf cats. Hear Res 343:118-127

Carrasco A, Lomber SG (2010) Reciprocal modulatory influences between tonotopic and nontonotopic cortical fields in the cat. J Neurosci 30:1476-1487

Chabot N, Mellott JG, Hall AJ, Tichenoff EL, Lomber SG (2013) Cerebral origins of the auditory projection to the superior colliculus of the cat. Hear Res 300:33-45

Chabot N, Butler BE, Lomber SG (2015) Differential modification of cortical and thalamic projections to cat primary auditory cortex following early- and late-onset deafness. J Comp Neurol 523:2297-2320

Charbonneau V, Laremee M-E, Boucher V, Bronchti G, Boire D (2012) Cortical and subcortical projections to visual cortex in anopthalmic, enucleated and sighted mice. Eur J Neurosci 36:2949-2963

Clascá F, Llamas A, Reinoso-Suárez F (1997) Insular cortex and neighboring fields in the cat: a redefinition based on cortical microarchitecture and connections with the thalamus. J Comp Neurol 384:456-482

Clemo HR, Sharma GK, Allman BL, Meredith MA (2008) Auditory projections to extrastriate visual cortex: connectional basis for multisensory processing in 'unimodal' visual neurons. Exp Brain Res 191:37-47

Clemo HR, Lomber SG, Meredith MA (2016) Synaptic basis for cross-modal plasticity: enhanced supragranular dendritic spine density in anterior ectosylvian auditory cortex of the early deaf cat. Cereb Cortex 26:1365-1376

Clemo HR, Lomber SG, Meredith MA (2017) Synaptic distribution and plasticity in primary auditory cortex (A1) exhibits laminar and cell-specific changes in the deaf. Hear Res 353:122-134

Dahmen JC, King AJ (2007) Learning to hear: plasticity of auditory cortical processing. Curr Opin Neurobiol 17:456-464

Eggermont JJ (2008) The role of sound in adult and developmental auditory cortical plasticity. Ear Hear 29:819-829

Finney EM, Fine I, Dobkins KR (2001) Visual stimuli activate auditory cortex in the deaf. Nat Neurosci 4:1171-1173

Finney EM, Clementz BA, Hickok G, Dobkins KR (2003) Visual stimuli activate auditory cortex in deaf subjects: evidence from MEG. NeuroReport 14:1425-1427

Horsley V, Clarke RH (1908) The structure and function of the cerebellum examined by a new method. Brain Behav Evol 31:45-124

Hunt DL, Yamoah EN, Krubitzer L (2006) Multisensory plasticity in congenitally deaf mice: how are cortical areas functionally specified? Neuroscience 139:1507-1524 
Imig TJ, Reale RA (1980) Patterns of cortico-cortical connections related to tonotopic maps in cat auditory cortex. J Comp Neurol 192:293-332

Jones TA, Leake PA, Snyder RL, Stakhovskaya O, Bonham B (2007) Spontaneous discharge patterns in cochlear spiral ganglion cells before the onset of hearing in cats. J Neurophysiol 98:1898-1908

Karlen SJ, Kahn DM, Krubitzer L (2006) Early blindness results in abnormal corticocortical and thalamocortical connections. Neuroscience 142:843-858

Karns CM, Dow MW, Neville HJ (2012) Altered cross-modal processing in the primary auditory cortex of congenitally deaf adults: a visual-somatosensory fMRI study with a double-flash illusion. J Neurosci 32:9626-9638

Kok MA, Chabot N, Lomber SG (2014) Cross-modal reorganization of cortical afferents to dorsal auditory cortex following earlyand late-onset deafness. J Comp Neurol 522:654-675

Kral A, Schröder J-H, Klinke R, Engel AK (2003) Absence of crossmodal reorganization in the primary auditory cortex of congenitally deaf cats. Exp Brain Res 153:605-613

Lambertz N, Gizewski ER, de Greiff A, Forsting M (2005) Crossmodal plasticity in deaf subjects dependent on the extent of hearing loss. Brain Res Cogn Brain Res 25:884-890

Lapper SR, Bolam JP (1991) The anterograde and retrograde transport of neurobiotin in the central nervous system of the rat: comparison with biocytin. J Neurosci Methods 39:173-174

Lee CC, Winer JA (2008a) Connections of cat auditory cortex: I. Thalamocortical system. J Comp Neurol 507:1879-1900

Lee CC, Winer JA (2008b) Connections of cat auditory cortex: II. Commissural system. J Comp Neurol 507:1901-1919

Lee CC, Winer JA (2008c) Connections of cat auditory cortex: III. Corticocortical system. J Comp Neurol 507:1920-1943

Lee CC, Winer JA (2011) Convergence of thalamic and cortical pathways in cat auditory cortex. Hear Res 274:85-94

Lee DS, Lee JS, Oh SH, Kim SK, Kim JW, Chung JK, Lee MC, Kim CS (2001) Cross-modal plasticity and cochlear implants. Nature 409:149-150

Levänen S, Hamdorf D (2001) Feeling vibrations: enhanced tactile sensitivity in congenitally deaf humans. Neurosci Lett 301:75-77

Levänen S, Jousmäki V, Hari R (1998) Vibration-induced auditorycortex activation in a congenitally deaf adult. Curr Biol 8:869-872

Lomber SG, Meredith MA, Kral A (2010) Cross-modal plasticity in specific auditory cortices underlies visual compensations in the deaf. Nat Neurosci 13:1421-1427

Lomber SG, Meredith MA, Kral A (2011) Adaptive crossmodal plasticity in deaf auditory cortex: areal and laminar contributions to supranormal vision in the deaf. In: Green AM, Chapman CE, Kalaska JF, Lepore F (eds) Enhancing performance for action and perception, multisensory integration, neuroplasticity and neuroprosthetics. Elsevier, Amsterdam, pp 251-270

Malhotra S, Hall AJ, Lomber SG (2004) Cortical control of sound localization in the cat: unilateral cooling deactivation of 19 cerebral areas. J Neurophysiol 92:1625-1643

Mellott JG, van der Gucht E, Lee CC, Carrasco A, Winer JA, Lomber SG (2010) Areas of the cat auditory cortex as defined by neurofilament proteins expressing SMI-32. Hear Res 267:119-136

Meredith MA, Clemo HR (1989) Auditory cortical projection from the anterior ectosylvian sulcus (field AES) to the superior colliculus in the cat: an anatomical and electrophysiological study. J Comp Neurol 289:687-707

Meredith MA, Lomber SG (2011) Somatosensory and visual crossmodal plasticity in the anterior auditory field of early-deaf cats. Hear Res 280:38-47
Meredith MA, Lomber SG (2017) Species-dependent role of crossmodal connectivity among the sensory cortices. Hear Res 343:83-91

Meredith MA, Kryklywy J, McMillan AJ, Malhotra S, Lum-Tai R, Lomber SG (2011) Crossmodal organization in the early deaf switches sensory, but not behavioral roles of auditory cortex. Proc Nat Acad Sci 108:8856-8861

Meredith MA, Clemo HR, Corley SB, Chabot N, Lomber SG (2016) Cortical and thalamic connectivity of the auditory anterior ectosylvian cortex of early-deaf cats: implications for neural mechanisms of crossmodal plasticity. Hear Res 333:25-36

Merzenich MM, Knight PL, Roth GL (1975) Representation of cochlea within primary auditory cortex in the cat. J Neurophys 38:231-249

Merzenich MM, Nelson RJ, Stryker MP, Cyander MS, Schoppmann A, Zook JM (1984) Somatosensory cortical map changes following digit amputation in adult monkeys. J Comp Neurol 224:591-605

Mezzera C, Lopez-Bendito G (2016) Cross-modal plasticity in sensory deprived animal models: from the thalamocortical development point of view. J Chem Neuroanat 75:32-40

Middlebrooks JC, Xu L, Clock Eddins A, Green DM (1998) Codes for sound-source localization in nontonotopic auditory cortex. J Neurophysiol 80:863-881

Neville HJ, Schmidt A, Kutas M (1983) Altered visual-evoked potentials in congenitally deaf adults. Brain Res 266:127-132

O'Leary DD, Chou SJ, Sahara S (2007) Area patterning of the mammalian cortex. Neuron 2:252-269

Olfert ED, Cross BM, McWilliam AA (1993) Guide to the care and use of experimental animals. Canadian Council on Animal Care, Ottawa, Ontario, Canada

Palmer LA, Rosenquist AC, Tusa RJ (1978) The retinotopic organization of lateral suprasylvian visual areas in the cat. J Comp Neurol 177:237-256

Payne BR, Lomber SG (1996) Age dependent modification of cytochrome oxidase activity in the cat dorsal lateral geniculate nucleus following removal of primary visual cortex. Vis Neurosci 13:805-816

Pekkola J, Ojanen V, Autti T, Jaaskelainen IP, Mottonen R, Tarkiainen A, Sams M (2005) Primary auditory cortex activation by visual speech: an fMRI study at $3 \mathrm{~T}$. NeuroReport $16: 125-128$

Rajakumar N, Elisevice K, Flumerfelt BA (1993) Biotinylated dextran: a versatile anterograde and retrograde neuronal tracer. Brain Res 607:47-53

Rauschecker JP, Grunau M, Poulin C (1987) Centrifugal organization of direction preferences in the cat's lateral suprasylvian visual cortex and its relation to flow field processing. J Neurosci 7:943-958

Reale RA, Imig TJ (1980) Tonotopic organization in auditory cortex of the cat. J Comp Neurol 192:265-291

Rouiller EM, Hornung JP, De Ribaupierre F (1989) Extrathalamic ascending projections to physiologically identified fields of the cat auditory cortex. Hear Res 40:233-246

Sadato N, Okada T, Honda M, Yonekura Y (2002) Critical period for cross-modal plasticity in blind humans: a functional MRI study. NeuroImage 16:389-400

Scannell JW, Blakemore C, Young MP (1995) Analysis of connectivity in the cat cerebral cortex. J Neurosci 15:1463-1483

Scannell JW, Sengpiel F, Tovee MJ, Benson PJ, Blakemore C, Young MP (1996) Visual motion processing in the anterior ectosylvian sulcus of the cat. J Neurophys 76:895-907

Schreiner CE, Cyander MS (1984) Basic functional organization of second auditory cortical field (AII) of the cat. J Neurophys 51:1284-1305 
Sternberger LA, Sternberger NH (1983) Monoclonal antibodies distinguish phosphorylated and nonphosphorylated forms of neurofilaments in situ. Proc Natl Acad Sci USA 80:6126-6130

Stewart DL, Starr A (1970) Absence of visually influenced cells in auditory cortex of normal and congenitally deaf cats. Exp Neurol 28:525-528

Striem-Amit E, Ovadia-Caro S, Caramazza A, Margulies DS, Villringer A, Amedi A (2015) Functional connectivity of visual cortex in the blind follows retinotopic organization principles. Brain 138:1679-1695

Takesian AE, Hensch TK (2013) Balancing plasticity/stability across brain development. Prog Brain Res 207:3-34

van der Gucht E, Vandesande F, Arckens L (2001) Neurofilament protein: a selective marker for the architectonic parcellation of the visual cortex in adult cat brain. J Comp Neurol 441:345-368

Veenman CL, Reiner A, Honig MG (1992) Biotinylated dextran amine as an anterograde tracer for single- and double-labeling studies. J Neurosci Methods 41:239-254 von Grünau MW, Sumbroicj TJ, Poulin C (1987) Visual receptive field properties in the posterior suprasylvian cortex of the cat: a comparison between the areas PMLS and PLLS. Vis Res $27: 343-356$

Wong C, Chabot N, Kok MA, Lomber SG (2014) Modified areal cartography in auditory cortex following early- and late-onset deafness. Cereb Cortex 24:1778-1792

Wong C, Chabot N, Kok MA, Lomber SG (2015) Amplified somatosensory and visual cortical projections to a core auditory area, the anterior auditory field, following early- and late-onset deafness. J Comp Neurol 523:1925-1947

Xu SA, Shepherd RK, Chen Y, Clark GM (1993) Profound hearing loss in the cat following the single co-administration of kanamycin and ethacrynic acid. Hear Res 70:205-215

Xu L, Furukawa S, Middlebrooks JC (1998) Sensitivity to soundsource elevation in nontonotopic auditory cortex. J Neuruphysiol 80:883-894 